\title{
Cardiac Lead Event Finding
}

National Cancer Institute

\section{Source}

National Cancer Institute. Cardiac Lead Event Finding. NCI Thesaurus. Code C99896.

Events pertaining to observations about implantable cardiac leads. 